\title{
Abordagem endodôntica não cirúrgica em extensa lesão periapical: relato de caso
}

Non-surgical endodontic approach in extensive periapical lesion: case report

Abordaje endodóntico no quirúrgico en extensa lesión periapical: reporte de caso

Mailon Cury CARNEIRO ${ }^{1}$

Fernanda Angelio DA COSTA ${ }^{1}$

Paula Gabriela Vieira CHICORA ${ }^{1}$

Marcos Sergio ENDO

Vanessa Cristina VELTRINI ${ }^{3}$

${ }^{1}$ Curso de Graduação em Odontologia - Departamento de Odontologia (DOD), Centro de Ciências da Saúde (CCS), Universidade Estadual de Maringá (UEM) 87083-170 Maringá -PR, Brasil

${ }^{2}$ Doutor, professor da disciplina de Endodontia - Departamento de Odontologia (DOD), Centro de Ciências da Saúde (CCS), Universidade Estadual de Maringá (UEM) 87083-170 Maringá-PR, Brasil

${ }^{3}$ Doutora, professora da disciplina de Patologia Bucal - Departamento de Odontologia (DOD), Centro de Ciências da Saúde (CCS), Universidade Estadual de Maringá (UEM) 87083-170 Maringá-PR, Brasil

\section{Resumo}

O objetivo deste trabalho é relatar um caso clínico de uma extensa lesão periapical em maxila, tratada somente por uma abordagem endodôntica não cirúrgica, com expressivo reparo periapical. Paciente do sexo feminino, 52 anos, compareceu à clínica odontológica, com a queixa principal de "cisto crescendo na boca". Os dentes 13, 14 e 15 apresentavam-se sem vitalidade pulpar. Os exames radiográficos mostraram duas áreas radiolúcidas, uniloculares, envolvendo os ápices dos dentes 13 e 15, ambos sem sinais de intervenção endodôntica. As áreas eram sugestivas de granuloma periapical e cisto periapical inflamatório, respectivamente. Realizou-se tratamento endodôntico dos dentes 13, 14 e 15. Após 11 meses, notou-se regressão significativa da rarefação óssea periapical, não sendo necessária qualquer intervenção cirúrgica. A paciente continuará em proservação até a remissão completa da lesão. O preparo químico-mecânico, associado ao emprego de medicação intracanal, pode ser suficiente para o reparo de lesões periapicais extensas. Sugere-se que o tratamento conservador seja sempre a primeira opção em casos semelhantes, de forma a se evitar cirurgias parendodônticas invasivas desnecessárias.

Descritores: Endodontia; Cisto Radicular; Tratamento Conservador.

\section{Abstract}

The aim of this study is to report a clinical case of a large periapical lesion in maxilla, treated only by a non-surgical endodontic approach, with expressive periapical repair. A 52-year-old female patient attended the dental clinic with a chief complaint of "a cyst growing in mouth". Teeth 13, 14 and 15 were without pulp vitality. Radiographic examinations showed two radiolucent and unilocular areas, suggestive of periapical granuloma and periapical inflammatory cyst, respectively, involving 13 and 15 apices, which did not present any endodontic intervention. Endodontic treatment was performed on the teeth 13, 14 and 15. After 11 months, significant regression of the periapical bone rarefaction was observed, and no surgical approach was required. The patient will be kept in follow-up until complete remission of the lesion. The chemical-mechanical preparation, associated with the use of intracanal medication, may be enough to promote repair of extensive lesions. It is suggested that the conservative treatment be always the first option in similar cases, avoiding unnecessary invasive parendodontic surgeries.

Descriptors: Endodontics; Radicular Cyst; Conservative Treatment.

\section{Resumen}

El objetivo del presente trabajo es relatar un caso clínico de una lesión maxilar periapical extensa tratada con un abordaje endodóntico no quirúrgico, con reparación periapical significativa. Una paciente de 52 años acudió a la clínica odontológica quejándose de "quiste que crece en la boca". Los dientes 13, 14 y 15 no presentaban vitalidad pulpar. Los exámenes radiográficos mostraron dos áreas radiolúcidas uniloculares que envolvían los ápices de los dientes 13 y 15, ambas sin signos de intervención endodóntica. Las áreas sugerían granuloma periapical y quiste periapical inflamatorio, respectivamente. Fue realizado el tratamiento endodóntico de los dientes 13,14 y 15 . Después de 11 meses, se observó una regresión significativa de la rarefacción ósea periapical, no necesitando intervención quirúrgica. La paciente continuará em acompañamiento hasta la remisión completa de la lesión. La preparación químico-mecánica asociada al uso de medicación intracanal puede ser suficiente para la reparación de lesiones periapicales extensas. Siempre se sugiere que el tratamiento conservador sea la primera opción en casos similares para evitar una cirugía parendodóntica invasiva innecesaria.

Descriptores: Endodoncia; Quiste Radicular; Tratamiento Conservador.

INTRODUÇÃO

As periapicopatias inflamatórias são lesões exclusivas de periápice, que se desenvolvem como resposta à invasão de microrganismos e seus subprodutos nos sistemas de canais radiculares ${ }^{1}$. A maioria ocorre após necrose pulpar e se observa por meio de radiografias de rotina. São, em geral, abscessos periapicais crônicos, granulomas periapicais e cistos radiculares ${ }^{2}$.

O tratamento pode ser desafiador. Anteriormente, a intervenção cirúrgica era a primeira opção para lesões periapicais extensas. Ainda hoje, é o tratamento preferido, particularmente em casos de lesões com longo tempo de evolução ${ }^{2}$. No entanto, há uma tendência para se optar por tratamentos conservadores, inicialmente, recorrendo a intervenções cirúrgicas apenas mediante persistência da lesão ${ }^{2}$.

O objetivo do presente artigo é relatar um caso clínico de uma extensa lesão periapical em maxila, tratada somente por uma abordagem endodôntica não cirúrgica, com expressivo reparo periapical.

\section{CASO CLÍNICO}

Paciente do sexo feminino, 52 anos, compareceu à clínica odontológica com queixa principal de "cisto crescendo na boca", há aproximadamente um ano, com extravasamento de secreção purulenta. Ao exame físico intrabucal observou-se discreto abaulamento do palato duro, lado direito. No dente 14, havia uma restauração provisória (Figura 1). O teste de sensibilidade pulpar foi negativo para os dentes 13, 14 e 15. As radiografias panorâmica (Figura 2A) e periapical (Figura 2B) exibiram duas áreas radiolúcidas, uniloculares, de formato circular, com 
aproximadamente $3,0 \mathrm{~cm}$ e $0,5 \mathrm{~cm}$, respectivamente, envolvendo os ápices dos dentes 13 e 15, ambos não obturados.

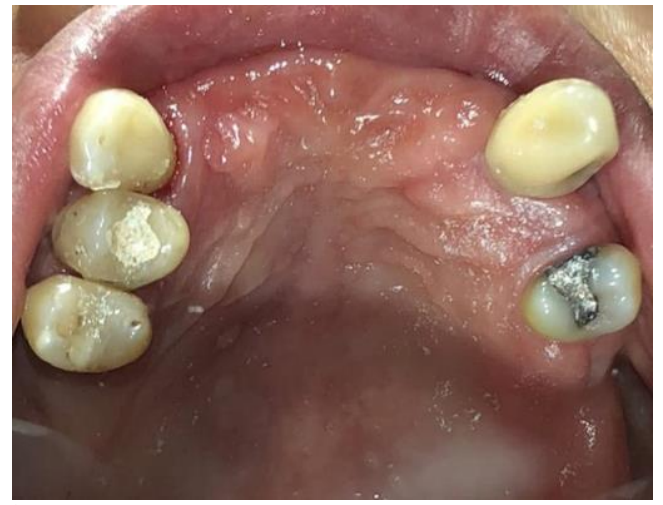

Figura 1: Foto intrabucal, mostrando ausência de vários dentes e discreto abaulamento do lado direito do palato duro.

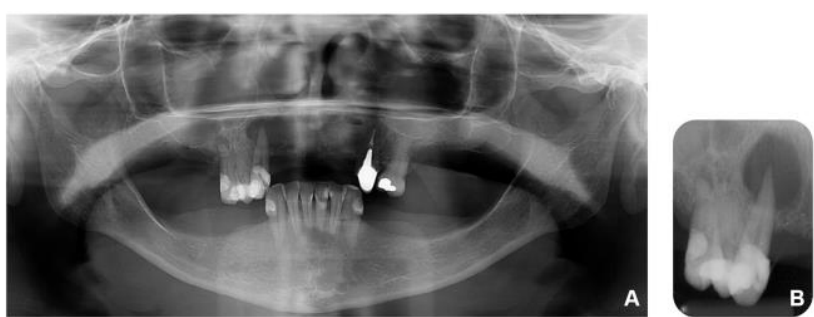

Figura 2: Radiografias panorâmica (A) e periapical (B), exibindo duas áreas radiolúcidas, uniloculares, envolvendo os dentes 13 e 15 , sem sinais de tratamento endodôntico.

O diagnóstico presuntivo da rarefação óssea presente no ápice do dente 15 foi granuloma periapical. Já a do dente 13, pelo tamanho e história clínica associados, era compatível com cisto radicular abscedado. A confirmação diagnóstica requer análise histopatológica. Independente da comprovação, entretanto, o protocolo de tratamento não difere e implica em desinfecção dos condutos radiculares. Como conduta inicial, optou-se pelo tratamento endodôntico convencional dos dentes 13, 14 e 15 . Todos apresentavam diagnóstico de necrose pulpar, sendo que os dentes 13 e 15 exibiam, também, lesão apical. Caso não houvesse regressão da rarefação óssea associada ao ápice do dente 13, seria realizada cirurgia parendodôntica, seguida de enucleação da lesão. No dente 13, após abertura coronária, fez-se exploração do canal radicular, sob irrigação com hipoclorito de sódio 1\% (Asfer, São Caetano do Sul, São Paulo, Brasil). Posteriormente, procedeu-se a odontometria, obtendo-se o comprimento de trabalho de $23 \mathrm{~mm}$. Realizou-se a patência foraminal, com uma lima K \#15 (Dentsply Maillefer, Ballaigues, Vaud, Suiça), $1 \mathrm{~mm}$ além do comprimento real do dente, inundado com a solução irrigadora. Determinou-se a lima anatômica inicial K \#20 (Dentsply Maillefer, Ballaigues, Vaud, Suiça). Durante o preparo químicomecânico, fez-se batente apical e, subsequentemente, escalonamento, a partir da técnica escalonada com recuo progressivo programado. Após isso, aplicou-se EDTA 17\% (Biodinâmica, Ibiporã, Paraná, Brasil) no interior do canal, deixando-o agir por 3 minutos, para remoção da smear layer. A medicação intracanal de escolha foi a associação de propilenoglicol (Biodinâmica, Ibiporã, Paraná, Brasil), hidróxido de cálcio $\left[\mathrm{Ca}(\mathrm{OH})_{2}\right]$ (Biodinâmica, Ibiporã, Paraná, Brasil) e paramonoclorofenol canforado (PMCC) (Biodinâmica, Ibiporã, Paraná, Brasil), devido à presença de lesão. Duas semanas depois, o dente foi obturado pela técnica da condensação lateral, com o cimento endodôntico Endofill (Dentsply Maillefer, Ballaigues, Vaud, Suiça). Os tratamentos endodônticos dos dentes 14 e 15 foram realizados da mesma forma (Figura 3). Todos receberam restauração com resina composta (Charisma, São Paulo, Brasil).
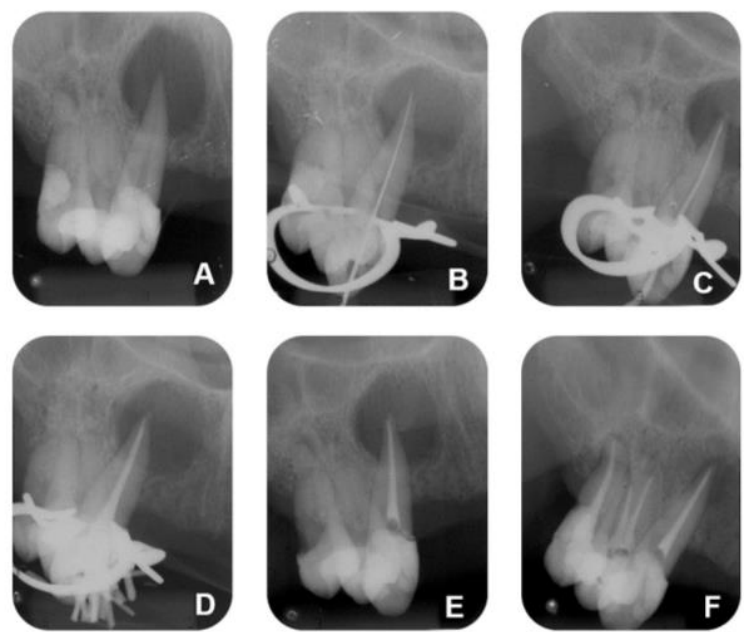

Figura 3: Radiografias periapicais do tratamento endodôntico do dente 13. A) Radiografia inicial; B) Odontometria; C) Prova do cone; D) Qualidade da obturação; E) Radiografia final; F) Onze meses após o tratamento.

No último retorno da paciente para proservação, 11 meses após o término do tratamento, as lesões apresentavam regressão considerável, não sendo necessária qualquer intervenção cirúrgica. Mesmo assim, a paciente será acompanhada até a remissão completa.

DISCUSSÃO

As lesões periapicais são resultantes de um processo inflamatório que afeta tecidos moles e duros das proximidades da raiz dentária. Como polpa e periápice se comunicam via forame apical, o agente agressor é o próprio tecido pulpar necrótico, onde microrganismos se desenvolvem e liberam toxinas ${ }^{3}$.

Abscessos periapicais crônicos, granulomas periapicais e cistos periapicais são periapicopatias inflamatórias crônicas ${ }^{2}$. A incidência varia de $28,7 \%$ a $70,07 \%$ para os abscessos ${ }^{4}$, de $9,3 \%$ a $87,1 \%$ para os granulomas e de 6 a $55 \%$ para os cistos periapicais ${ }^{5}$.

Os abscessos periapicais crônicos caracterizam-se por rarefação óssea difusa e pela presença de drenagem purulenta, por isso, há pouco ou nenhum desconforto para o paciente ${ }^{6}$. Eles diferem muito das formas agudas, que são de aparecimento rápido, geram dor espontânea e edema nos tecidos moles, além de mal estar, febre e linfadenopatia, sem sinais radiográficos evidentes ${ }^{6}$. 
No granuloma periapical, há tecido conjuntivo infiltrado por células inflamatórias mononucleares ${ }^{6}$. Já nos cistos periapicais inflamatórios, também chamados cistos radiculares, há lúmen, cápsula conjuntiva e epitélio de revestimento, em geral pavimentoso estratificado não queratinizado, originário dos restos epiteliais de Malassez ${ }^{7}$. Ambas as lesões têm apresentação radiográfica muito similar. Os cistos, no entanto, costumam ser maiores e ter orla radiopaca ${ }^{8,9}$. O diagnóstico conclusivo requer análise histopatológica ${ }^{10}$. Os cistos também podem se infectar secundariamente e apresentar conteúdo purulento, sendo chamados de cistos abscedados ${ }^{11}$.

As opções terapêuticas para lesões periapicais mais extensas podem variar de tratamento endodôntico convencional não cirúrgico até intervenções mais invasivas ${ }^{3,12}$. O convencional deve ser sempre a primeira escolha, visto que a eliminação bacteriana do conduto radicular é crucial e pode ser resolutiva $^{3,13}$. Há situações, entretanto, em que é preciso associá-lo à descompressão ou marsupialização, ou mesmo à enucleação da lesão ${ }^{14}$.

Caliskan $^{15}$ apontou $73,8 \%$ de sucesso com tratamento não cirúrgico de lesões periapicais extensas, utilizando o $\mathrm{Ca}(\mathrm{OH})_{2}$. Em $70 \%$ dos casos, para um reparo completo, alguns autores relatam ser necessário um período de pelo menos dois anos ${ }^{15,16}$, mas a maior parte da regressão se dá nos 12 primeiros meses ${ }^{17}$. De fato, no presente caso, em menos de um ano, a lesão regrediu quase que integralmente.

Para aumentar as chances de um tratamento endodôntico convencional promover resolução completa de lesão apical extensa, enfatizamos a importância de criteriosa instrumentação, irrigação abundante e eficaz, realização da patência foraminal $^{18}$, além de adequado preparo biomecânico, seguido por medicação intracanal ${ }^{19}$. $\mathrm{O} \mathrm{Ca}(\mathrm{OH})_{2}$, utilizado no presente caso, tem sido muito recomendado, por apresentar propriedades antiinflamatórias e antibacterianas, neutralizar produtos ácidos e ativar a fosfatase alcalina ${ }^{19,20}$. Sua ação antibacteriana se dá por desnaturação proteica, danos à membrana plasmática e ao DNA. Ele também inativa as endotoxinas de bactérias gramnegativas $^{19,21}$.

Alguns estudos recomendam misturar $\mathrm{O}$ $\mathrm{Ca}(\mathrm{OH})_{2}$ a outras substâncias ${ }^{19,22}$. O PMCC, também utilizado na paciente em questão, é uma opção. Do ponto de vista físico-químico, tal associação proporciona melhor difusão nos túbulos dentinários e nas ramificações do canal radicular ${ }^{23}$. Também apresenta maior tempo de ação, devido à liberação progressiva de íons cálcio e hidroxila do paraclorofenolato de cálcio, que é o sal formado pela reação entre $\mathrm{Ca}(\mathrm{OH})_{2}$ e PMCC. Sua presença residual também resulta em um espectro antimicrobiano mais amplo, com redução inflamatória pela diminuição de radicais livres oxigenados. A associação também estimula proliferação de fibroblastos e de células osteogênicas da medula óssea, propiciando o reparo tecidual ${ }^{23}$.

CONCLUSÃO

O presente caso ilustra o tratamento convencional como opção terapêutica inicial de escolha para lesões periapicais extensas, especialmente se manobras de desinfecção do conduto forem adotadas, incluindo a realização da patência foraminal e a combinação de $\mathrm{Ca}(\mathrm{OH})_{2}$ a $\mathrm{PMCC}$, em propilenoglicol como veículo.

\section{REFERÊNCIAS}

1. Hammouti J, Chhoul H, Ramdi H. Non-surgical management of large periapical cyst like lesion: case report and litterature review. J Oral Heal Dent Sci. 2019;3(1):1-7.

2. Mitra A, Adhikari C. Management of large periapical lesions by non surgical endodontic approach - two case reports. IJIRDS. 2017;2(5):97-104.

3. Al Khasawnah Q, Hassan F, Malhan D, Engelhardt M, Daghma DES, Obidat D, et al. Nonsurgical clinical management of periapical lesions using calcium hydroxide-iodoformsilicon-oil paste. Biomed Res Int. 2018;2018:1-8.

4. Schulz M, von Arx T, Altermatt HJ, Bosshardt D. Histology of periapical lesions obtained during apical surgery. JOE. 2009;35(5):634-42.

5. Ramachandran Nair PN, Pajarola G, Schroeder HE. Types and incidence of human periapical lesions obtained with extracted teeth. Oral Surg Oral Med Oral Pathol Oral Radiol Endod. 1996;81(1):93-102.

6. Gutmann JL, Baumgartner JC, Gluskin AH, Hartwell GR, Walton RE. Identify and define all diagnostic terms for periapical/periradicular health and disease states. JOE. 2009;35(12):1658-74.

7. Antoh M, Hasegawa H, Kawakami T, Kage T, Chino T, Eda S. Hyperkeratosis and atypical proliferation appearing in the lining epithelium of a radicular cyst. Report of a case. J CranioMaxillo-Facial Surg. 1983;21(5):210-13.

8. Natkin E, Oswald RJ, Carries LI. The relationship of lesion size to diagnosis, incidence, and treatment of periapical cysts and granulomas. Oral Surg. 1984;57(1):82-94.

9. Rathod DM, Mulay SA. Non-surgical treatment of large periapical lesion using various formulations of calcium hydroxide \& nd: yag laser. Int J Curr Res. 2017;9(8):56668-72.

10. Rosenberg PA, Frisbie J, Lee J, Lee K, Frommer $\mathrm{H}$, Kottal S, et al. Evaluation of pathologists (histopathology) and radiologists (cone beam computed tomography) differentiating radicular cysts from granulomas. J Endod. 2010;36(3):423-28. 
11. Sant'ana Filho M, Rados PV. Lesões apicais. In: Silveira JOL, Beltrão GC. Exodontia. 1Porto Alegre: Missau; 1998. cap. 22, p. 275-85.

12. Sood N, Maheshwari N, Gothi R, Sood N. Treatment of large periapical cyst like lesion: a noninvasive approach: a report of two cases. Int $\mathbf{J}$ Clin Pediatr Dent. 2015;8(2):133-37.

13. Singh U, Nagpal R, Sinha D, Tuhin, Tyagi N. Iodoform based calcium hydroxide paste (metapex):an aid for the healing of chronic periapical lesion. J Adv Res Biol Sci. 2013;6(1):63-7.

14. Dandotikar D, Peddi R, Lakhani B, Lata K, Mathur A, Chowdary UK. Nonsurgical management of a periapical cyst: a case report. J Int Oral Health. 2013;5(3):79-84.

15. Calişkan MK. Prognosis of large cyst-like periapical lesions following nonsurgical root canal treatment: a clinical review. Int Endod J. 2004;37(6):408-16.

16. Kanmaz F, Altunbaş D, Zan R, Akpınar KE. Nonsurgical endodontic treatment of a large periradicular lesion. Turk Endod J. 2017;2(1):21-4.

17. Öztan MD. Endodontic treatment of teeth associated with a large periapical lesion. Int Endod J. 2002;35(1):73-8.

18. Barroso JAY, Uchimura JYT, Endo MS, Pavan NNO, Queiroz AF. Avaliação in vitro da influência da lima patência na manutenção do comprimento de trabalho. Rev Odontol UNESP. 2017;46(2):72-6.

19. Madhusudhana K, Surada R, Kumar CS, Lavanya A. Non-surgical management of a large periapical lesion: a case report. Ann Essences Dent. 2017;9(2):22-5.

20. Soares J, Santos S, Silveira F, Nunes E. Nonsurgical treatment of extensive cyst-like periapical lesion of endodontic origin. Int Endod J. 2006;39(7):566-75.

21. Mohammadi Z, Shalavi S, Yazdizadeh M. Antimicrobial activity of calcium hydroxide in endodontics: a review. Chonnam Med J. 2013;48(3):133-40.

22. Estrela C, Bammann LL, Pimenta FC, Pécora JD. Control of microorganisms in vitro by calcium hydroxide pastes. Int Endod J. 2001;34(5):341-45.

23. Soares JA, Brito-Júnior M, Silveira FF, Nunes E, Santos SMC. Favorable response of an extensive periapical lesion to root canal treatment. J Oral Sci. 2008;50(1):107-11.

\section{CONFLITO DE INTERESSES}

Os autores declaram não haver conflitos de interesse.

\section{AUTOR PARA CORRESPONDÊNCIA}

\section{Mailon Cury Carneiro}

Rua Professor Lauro Eduardo Werneck, 1023

Telefone/Fax: +55 42 99984-9539

E-mail: mailoncury@gmail.com

Submetido em 07/10/2019

Aceito em 05/06/2020 